\title{
STRUCTURAL STUDY OF GaN(As,P) LAYERS GROWN ON (0001) GaN BY GAS SOURCE MOLECULAR BEAM EPITAXY
}

\author{
Tae-Yeon Seong, ${ }^{\text {a),c) }}$ In-Tae Bae, ${ }^{\text {a) }}$ Y. Zhao, ${ }^{\text {b) }}$ and C.W. Tu ${ }^{\text {b) }}$ \\ ${ }^{\text {a)} D e p t . ~ o f ~ M a t e r i a l s ~ S c i e n c e ~ a n d ~ E n g i n e e r i n g, ~ K w a n g j u ~ I n s t i t u t e ~ o f ~ S c i e n c e ~ a n d ~ T e c h n o l o g y ~(K-~}$ \\ JIST), Kwangju 500-712, Korea, ${ }^{c}$ Electronic mail: tyseong@kjist.ac.kr

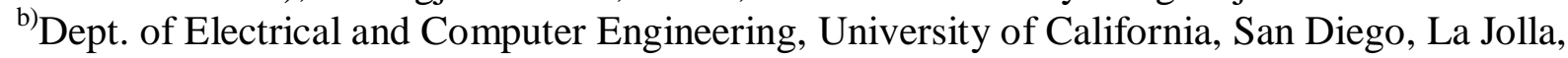
CA 92093-0407

Cite this article as: MRS Internet J. Nitride Semicond. Res. 4S1, G3.11 (1999)

\begin{abstract}
Transmission electron microscope (TEM) and transmission electron diffraction (TED) examination has been performed to investigate microstructural properties of gas source molecular beam epitaxial $\mathrm{GaN}(\mathrm{As}, \mathrm{P})$ layers grown on (0001) GaN/sapphire at temperatures in the range $500-760{ }^{\circ} \mathrm{C}$. As for the GaNAs, we report the observation of ordering with a space group $P 3 \mathrm{~m} 1$ in the layer grown at $730{ }^{\circ} \mathrm{C}$. The layers grown at temperatures below $600{ }^{\circ} \mathrm{C}$ are polycrystalline, whist the $730^{\circ} \mathrm{C}$ GaNAs layer has epitaxial relation to the GaN substrate. It is also shown that the GaNAs layers experience a structural change from a zinc-blende phase to a wurtzite phase, as the growth temperature increases. As for the GaNP, it is shown that the layers grown at temperatures $\leq 600{ }^{\circ} \mathrm{C}$ experience phase separation resulting in a mixture of GaN-rich and GaP-rich GaNP with zinc-blende structure. However, the layers grown at temperatures $\geq 730$ ${ }^{\circ} \mathrm{C}$ are found to be binary zinc-blende $\mathrm{GaN}(\mathrm{P})$ single crystalline materials. The layers grown at temperatures $\geq 730{ }^{\circ} \mathrm{C}$ consist of two types of micro-domains, i.e., $\mathrm{GaN}(\mathrm{P})_{\mathrm{I}}$ and $\mathrm{GaN}(\mathrm{P})_{\mathrm{II}}$; the former having twin relation to the latter.
\end{abstract}

\section{INTRODUCTION}

Gallium nitride-based materials are of technological importance because of their applications in short wavelength optical devices, e.g. blue-green light emitting diodes (LEDs) and violet laser diodes (LDs). Due to a large bowing parameter, addition of As or P to gallium nitride could lead to the practical engineering of specific semiconductors having a wide range of wavelengths from ultra violet to larger than $2 \mu \mathrm{m}$.

Calculations based upon bulk thermodynamics indicated that a large miscibility gap exists for a GaN-GaP system where phase separation may occur by spinodal decomposition during layer growth.[1] The presence of such a miscibility gap would be a major obstacle for the successful growth of ternary GaNP alloy layers. Iwata et al.[2], investigating gas source molecular beam epitaxial (GSMBE) growth of $\mathrm{GaN}_{1-\mathrm{x}} \mathrm{P}_{\mathrm{x}}(\mathrm{x} \leq 0.015)$, showed that phase separation occurred for a high $\mathrm{PH}_{3}$ flow rate condition. $\mathrm{Bi}$ and $\mathrm{Tu}$ investigated $\mathrm{GaN}_{\mathrm{x}} \mathrm{P}_{1-\mathrm{x}}$ layers grown on $\mathrm{GaP}$ substrates at temperatures in the range $500-610^{\circ} \mathrm{C}$ by GSMBE using a $\mathrm{N}$ radical beam source.[3] They showed that $\mathrm{GaN}_{\mathrm{x}} \mathrm{P}_{1-\mathrm{x}}$ with a maximum $\mathrm{N}$ concentration of $16 \%$ was obtained, but no phase separation was observed.

In this article, we describe structural results obtained from transmission electron microscope (TEM) and transmission electron diffraction (TED) studies of GaN(As,P) layers grown on (0001) $\mathrm{GaN}$ at temperatures ranging from 500 to $760{ }^{\circ} \mathrm{C}$. 


\section{EXPERIMENT}

The GaN(As,P) layers were grown on MOVPE (0001) GaN/sapphire substrates in a modified GEN II MBE system. Pure elemental Ga was used as the group III source and thermally cracked phosphine was used as the group $\mathrm{V}$ source. $\mathrm{PH}_{3}$ flow rate was $3 \mathrm{sccm}$. A N radical beam source (Oxford Applied Research Model MPD21) was used to produce active N species and the RF power was fixed at $300 \mathrm{~W}$. $\mathrm{AsH}_{3}$, cracked at $1000{ }^{\circ} \mathrm{C}$, provided the $\mathrm{As}_{2}$ flux and its flow rate was between 0 and $3 \mathrm{sccm}$. The growth temperature ranged from 500 to $760{ }^{\circ} \mathrm{C}$ and the growth rate was 0.9 monolayer/s.

For electron microscope examination, [11-20] and [01-10] cross-section and [0001] planview thin foil specimens were prepared using standard procedures and finished by $\mathrm{Ar}^{+}$ion thinning with the specimens cooled to $77 \mathrm{~K}$. TEM, TED, and high resolution electron microscope (HREM) examination was performed in a JEM 2010 instrument operated at 200kV.

\section{RESULTS AND DISCUSSION}

\section{A. The Growth of GaNAs Layers}

TED examination was made of orthogonal [2-1-10] and [01-10] cross-section samples to investigate the structural properties of the GaNAs layers, which were grown at temperatures in the range $500-730^{\circ} \mathrm{C}$. Fig. 1 shows a [01-10] TED pattern taken from a region of the thin foil specimen including the $500{ }^{\circ} \mathrm{C}$ GaNAs layer and the GaN substrate. The pattern exhibits wurtzite $\mathrm{GaN}$ spots and diffuse rings. The ring pattern is characteristic of polycrystalline materials. The polycrystalline material was identified from the measured spacings of the diffuse rings, assuming that the wurtzite $\mathrm{GaN}$ substrate spots correspond to undistorted materials with the bulk GaN lattice parameters, i.e., $a=0.3189 \mathrm{~nm}$ and $c=0.5185 \mathrm{~nm}$.[4] Measurements show that the rings are attributed to the zinc-blende $\mathrm{GaN}_{1-\mathrm{x}} \mathrm{As}_{\mathrm{x}}(\mathrm{x} \approx 0.012)$, where the lattice parameter of the zincblende $\mathrm{GaN}$ material was assumed to be $0.452 \pm 0.001 \mathrm{~nm}$.[5-7]

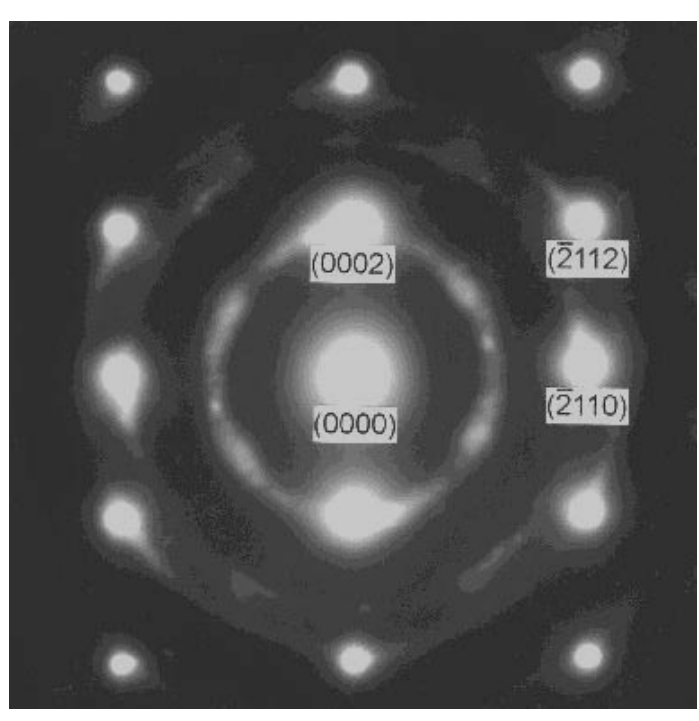

Fig.1. A [01-10] TED pattern obtained from a region of the thin foil specimen including the $500{ }^{\circ} \mathrm{C}$ GaNAs layer and the $\mathrm{GaN}$ substrate.
A TEM $\{-11-1\}$ dark field (DF) image was obtained from the [2-1-10] cross-section sample of the $500{ }^{\circ} \mathrm{C}$ layer to investigate microstructure. The image showed the columnar grains which are inclined $\sim 27^{\circ}$ from the $[0001]_{\mathrm{GaN}}$ direction. The grains varied in width from 3.5 to $6.5 \mathrm{~nm}$ and in length from 7.5 to $38 \mathrm{~nm}$.

Fig. 2 shows a cross-section [01-10] TED pattern $\left(\sim 5^{\circ}\right.$ away from the exact pole $)$ taken from the GaNAs layer grown at $730{ }^{\circ} \mathrm{C}$. The pattern exhibits sharp wurtzite GaNAs spots (using the GaN substrate spots as a reference), indicating the epitaxial growth of a wurtzite material. A [0002] DF image obtained from the $730{ }^{\circ} \mathrm{C}$ layer illustrated the growth of a single-crystalline layer with defects providing the main contrast.

Another interesting feature is the presence of forbidden extra spots in the [0110] TED pattern (Fig. 2) obtained from the 
GaNAs layer grown at $730{ }^{\circ} \mathrm{C}$. The pattern was obtained by tilting the specimen $\sim 5^{\circ}$ toward the

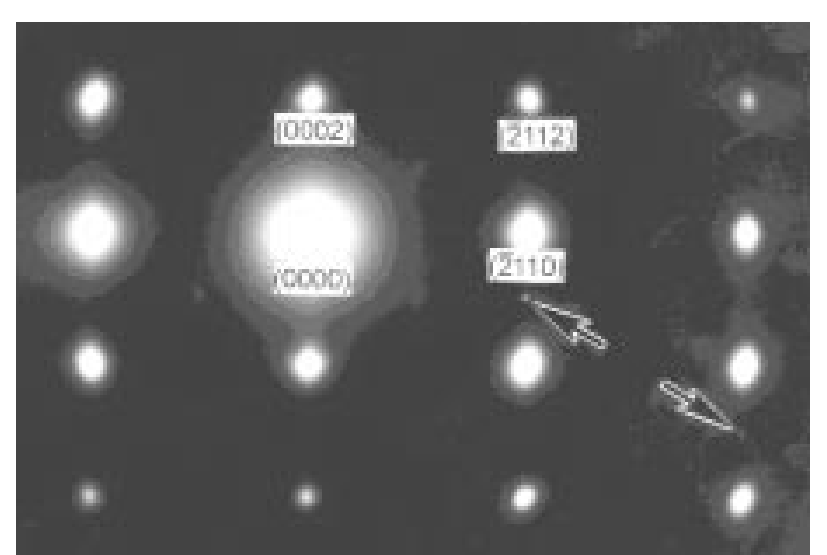

Fig.2. A [01-10] TED pattern obtained from the GaNAs layer grown at $730{ }^{\circ} \mathrm{C}$.

[2-1-1-4] direction. Such tilting was employed to get the superlattice spots excited, since they were extremely weak at the exact [01-10] pole. There are superlattice spots half way between the rows of the fundamental spots parallel to the [0001] direction, as indicated by the arrows. This is consistent with the existence of an ordered structure in the layer along the [0001] direction with a periodicity twice that of the wurtzite structure. The mixed group $\mathrm{V}$ atom sublattice of the ordered

GaNAs layer consists of alternating N-rich and As-rich (0001) planes. Similar ordering was observed in the mixed group III-nitride layers.[8,9] Ruterana et al.[9], investigating MOVPE InGaN layers grown on (0001) sapphire reported evidence for the formation of such ordering with a space group $P 3 \mathrm{~m} 1$. However, no superlattice-related structures were demonstrated.

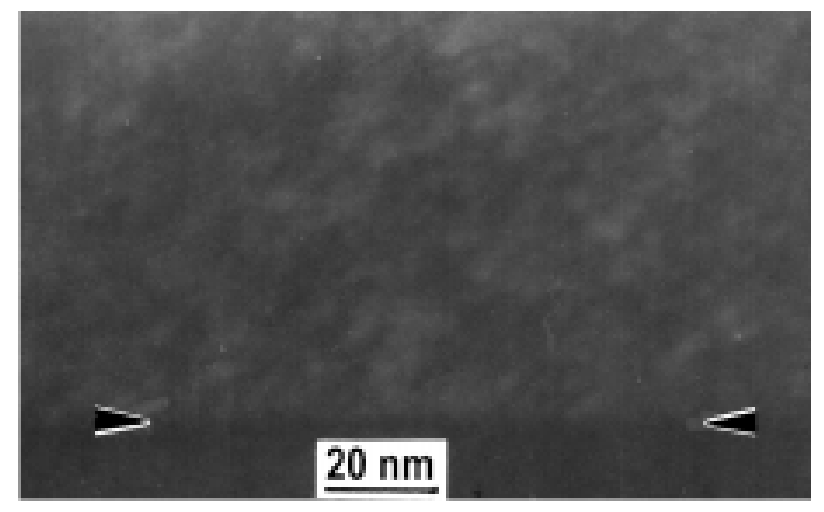

Fig. 3 A TEM DF image of the $730{ }^{\circ} \mathrm{C}$ layer taken using the forbidden (-211-1) spot.

Fig. 3 shows a DF image obtained from the $730{ }^{\circ} \mathrm{C}$ layer, which was recorded using the forbidden (-211-1) spot. The DF image revealed ordered domains as the small blobs. However, the contrast of the images was extremely weak. The interface between the overlayer and the substrate is indicated by the arrows. The domains varied in width from $\sim 1.8$ to $\sim 4.5 \mathrm{~nm}$ and in length from $\sim 4$ to $\sim 10 \mathrm{~nm}$, and were randomly distributed throughout the layer. The details will be published elsewhere.[10]

\section{B. The Growth of GaNP Layers}

TED examination was made of orthogonal [01-10] and [2-1-10] cross-section specimens to investigate the structural properties of the $\mathrm{GaN}_{1-\mathrm{x}} \mathrm{P}_{\mathrm{x}}$ layers that were grown at temperatures in the range $500-760{ }^{\circ} \mathrm{C}$. Fig. 4 shows a [01-10] TED pattern from a $500{ }^{\circ} \mathrm{C}$ layer and the $\mathrm{GaN}$ substrate. The pattern exhibits the wurtzite $\mathrm{GaN}$ spots and weak diffraction spots that are associated with the rings of diffuse diffracted intensity. The TED pattern shows that two different phases are present in the overlayer. The phases were identified from the measured spacings of the diffuse rings, assuming that the wurtzite $\mathrm{GaN}$ substrate spots correspond to undistorted materials with the bulk GaN lattice parameters, i.e., $a=0.3189 \mathrm{~nm}$ and $c=0.5185 \mathrm{~nm}$.[4] Measurements show that the rings are attributed to zinc-blende $\mathrm{GaN}_{1-\mathrm{x}} \mathrm{P}_{\mathrm{x}}(\mathrm{x} \approx 0.91$ and 0.01$)$, where the lattice parameter of the metastable zinc-blende $\mathrm{GaN}$ material was assumed to be $0.452 \pm 0.001 \mathrm{~nm}$.[5-7]

A similar TED pattern was obtained from the layer grown at $600{ }^{\circ} \mathrm{C}$. The characteristics of the pattern are similar to those of the $500{ }^{\circ} \mathrm{C}$ layer. However, some of the spots are associated with diffuse streaks approximately parallel to the $[-2112]_{\mathrm{GaN}}$ direction. Such streaks are attributed to inclined grains. In a similar manner, measurements show that the overlayer consists of two phases of zinc-blende $\mathrm{GaN}_{1-\mathrm{x}} \mathrm{P}_{\mathrm{x}}(\mathrm{x} \approx 0.88$ and 0.03$)$. 


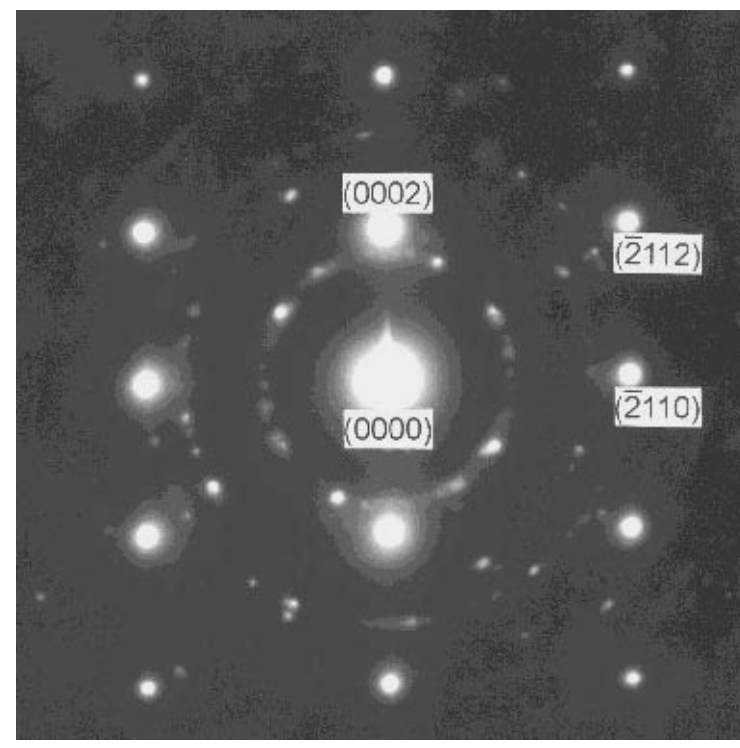

Fig. 4. A [01-10] TED pattern obtained from the layer grown at $500{ }^{\circ} \mathrm{C}$.
Fig. 5(a) shows a TED pattern from solely the $750{ }^{\circ} \mathrm{C}$ layer, being indexed in Fig. 5(b). The TED results show that [-111] and [110] of the zinc-blende overlayer are parallel to the c-axis and [2-1-10] of the wurtzite $\mathrm{GaN}$ substrate, respectively. The pattern from the overlayer exhibits two characteristic features: i) elongation of the diffracted spots; ii) presence of the two sets of $<110>$ patterns. The elongation of the spots can be attributed to some degrees of irregularity in the size of the $\mathrm{GaN}(\mathrm{P})$ domains. (The ' $\mathrm{GaN}(\mathrm{P})$ ' means that $\mathrm{P}$ is dissolved into binary zinc-blende GaN.) It is worth noting that there are two different types of zinc-blende crystal domains in the overlayer, i.e., $\mathrm{GaN}(\mathrm{P})_{\mathrm{I}}$ (indicated by 'open circle') and $\mathrm{GaN}(\mathrm{P})_{\mathrm{II}}$ (indicated by 'solid square') (Fig. 5(b)). The unit cell of the $\operatorname{GaN}(\mathrm{P})_{\text {II }}$ domains is rotated counterclockwise by $\sim 71^{\circ}$ about the [2$1-10]_{\mathrm{GaN}}$ direction with reference to that of the $\mathrm{GaN}(\mathrm{P})_{\mathrm{I}}$ domains. This rotation causes the $(-111)_{\mathrm{I}}$ and $(1-11)_{\text {II }}$ planes of the two domains to be parallel to each other, i.e., one having twin relation to the other. Measurements show that the lattice parameter of the $\mathrm{GaN}(\mathrm{P})_{\mathrm{I}}\left(\right.$ or $\left.\mathrm{GaN}(\mathrm{P})_{\mathrm{II}}\right)$ is fairly close to the zinc-blende $\mathrm{GaN}$, indicating
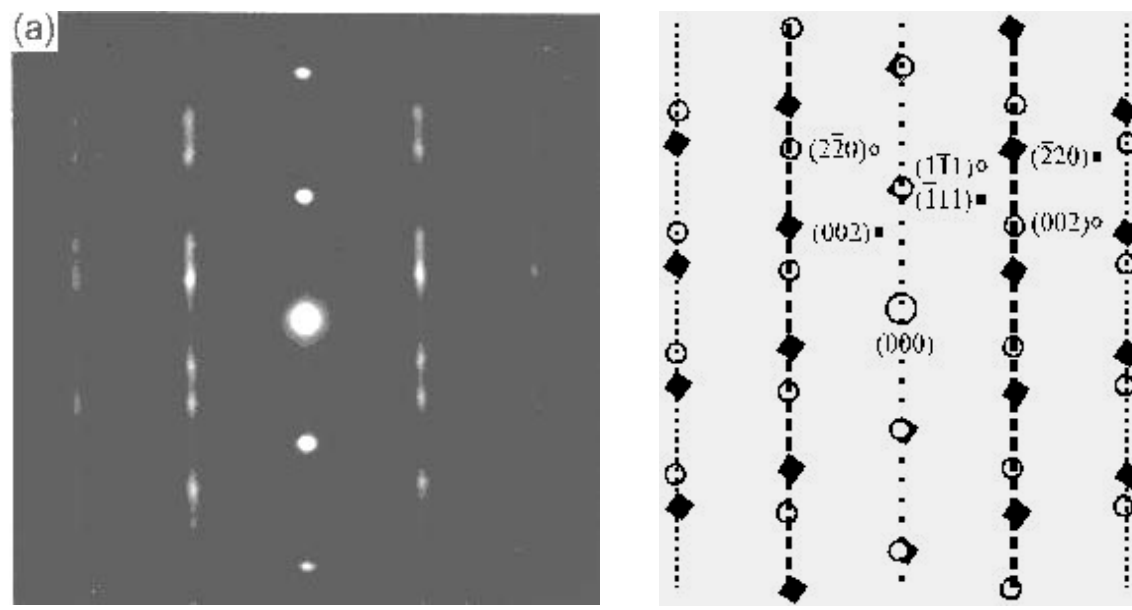

Fig. 5. (a) A TED pattern obtained from solely the $750{ }^{\circ} \mathrm{C}$ layer, which is indexed in (b).

that the phase is a binary alloy.

TEM bright field and DF images were obtained to observe the microstructures and phases of the $\mathrm{GaN}_{1-\mathrm{x}} \mathrm{P}_{\mathrm{x}}$ layers grown at temperatures between 500 and $760{ }^{\circ} \mathrm{C}$. For the $500{ }^{\circ} \mathrm{C}$ layer, the grains of the GaP-rich phase varied in width from $\sim 26$ to $\sim 123 \mathrm{~nm}$ and in height from $\sim 33$ to $\sim 73$ $\mathrm{nm}$, while those of the GaN-rich phase varied in width from $\sim 17$ to $\sim 156 \mathrm{~nm}$ and in height from $\sim 20$ to $\sim 40 \mathrm{~nm}$. For the $600{ }^{\circ} \mathrm{C}$ layer, the GaP-rich grains varied in width from $\sim 23$ to $\sim 50 \mathrm{~nm}$ and in height from $\sim 23$ to $\sim 150 \mathrm{~nm}$, while the GaN-rich grains varied in width from $\sim 17$ to $\sim 50$ $\mathrm{nm}$ and in height from $\sim 16$ to $\sim 116 \mathrm{~nm}$.

Fig. 6 shows a DF image obtained from the cross-section sample of the $750{ }^{\circ} \mathrm{C}$ layer, which was recorded using the (-11-1) spot of the $\operatorname{GaN}(\mathrm{P})_{\mathrm{I}}$. The image reveals fine needle-like contrast (termed here 'micro-domains') lying parallel to the layer surface. The micro-domains 
vary in thickness from $\sim 0.8$ to $\sim 2.5 \mathrm{~nm}$ and in length from $\sim 2$ to $\sim 10 \mathrm{~nm}$. A HREM image is shown enlarged in the inset right top, clearly illustrating the twin relation between the two domains of $\mathrm{GaN}(\mathrm{P})_{\mathrm{I}}$ and $\mathrm{GaN}(\mathrm{P})_{\mathrm{II}}$.

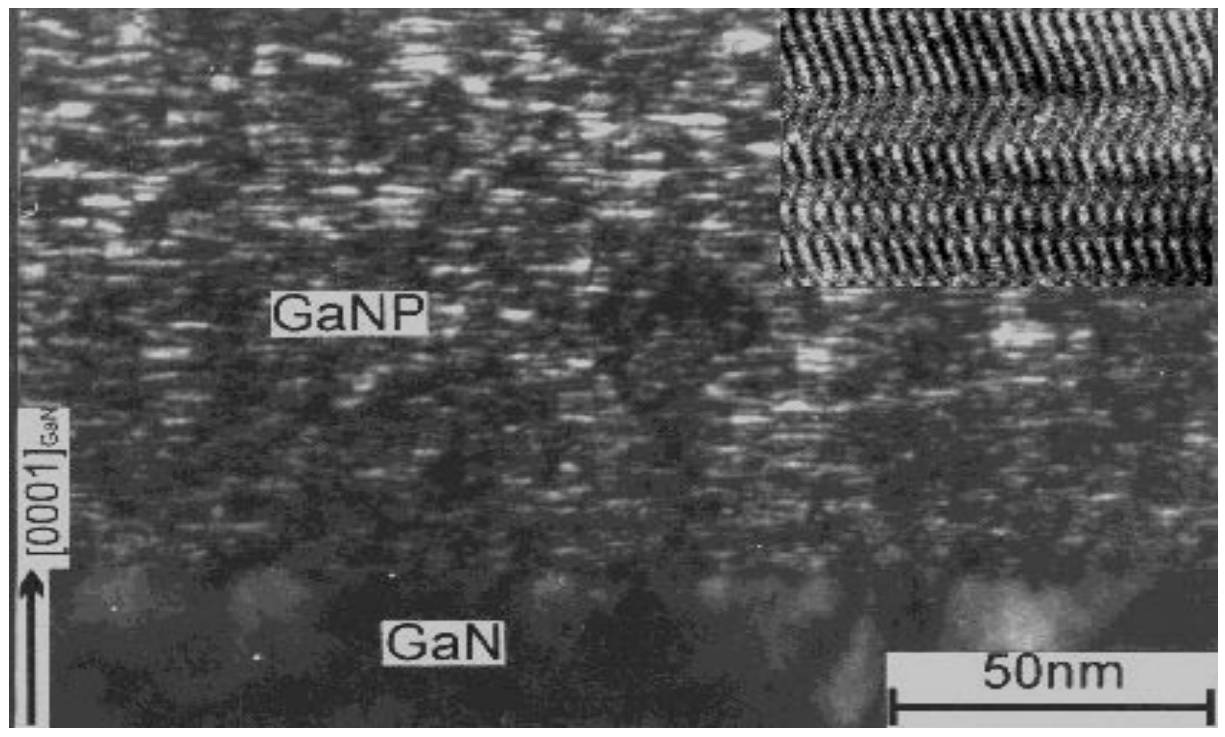

Fig. 6. A TEM dark field image obtained from the cross-section sample of the $750{ }^{\circ} \mathrm{C}$ layer, which was recorded using the (-11-1) spot of the $\mathrm{GaN}(\mathrm{P})_{\mathrm{I}}$.

$\mathrm{GaN}$ is a polytype material having two crystal structures of wurtzite and zinc-blende. The formation energies of the two phases are similar, although the wurtzite structure was calculated to be more stable than the zinc-blende.[11] This indicates that the crystal structure can be readily influenced by growth conditions. [7,12,13] It is worth noting that the only difference between the zinc-blende and wurtzite structures is the stacking sequence of the close-packed atomic layers. We found that GSMBE growth of pure $\mathrm{GaN}$ on (0001) GaN/sapphire at $730{ }^{\circ} \mathrm{C}$ led to a wurtzite phase. These results show that $\mathrm{P}$ plays an important role in the formation of the zinc-blende phase. Thus, the occurrence of the twin domains may be explained in terms of the uneven distribution of $\mathrm{P}$ at the growing surface. Local fluctuations in the $\mathrm{P}$ concentrations may cause a fault in the stacking order of the atomic layers, resulting in a number of twins and stacking faults, and hence the twin domains.

\section{CONCLUSION}

$\mathrm{GaN}(\mathrm{As}, \mathrm{P})$ layers grown on (0001) GaN/sapphire at temperatures ranging from 500 to 760 ${ }^{\circ} \mathrm{C}$ were examined by TEM and TED to investigate structural behaviour. For the GaNAs layers, ordering with a space group $P 3 \mathrm{ml}$ was found to occur in the $730{ }^{\circ} \mathrm{C}$ layer. The layers grown at temperatures $\leq 600{ }^{\circ} \mathrm{C}$ were polycrystalline, whist the growth at $730{ }^{\circ} \mathrm{C}$ led to an epitaxial GaNAs layer. For the $500{ }^{\circ} \mathrm{C}$ layer, the grains were of width $3.5-6.5 \mathrm{~nm}$ and of length $7.5-38$ $\mathrm{nm}$. It was also shown that the layers grown at temperatures $\leq 600{ }^{\circ} \mathrm{C}$ had a zinc-blende structure, while the $730{ }^{\circ} \mathrm{C}$ layer grew in a wurtzite form. As for the GaNP layers, it is shown that for growth at temperatures $\leq 600{ }^{\circ} \mathrm{C}$, phase separation occurred resulting in the formation of $\mathrm{GaN}$-rich and GaP-rich GaNP phases. However, growth at temperatures $\geq 730{ }^{\circ} \mathrm{C}$ led to a binary single crystal material, containing two types of micro-domains, i.e., $\mathrm{GaN}(\mathrm{P})_{\mathrm{I}}$ and $\mathrm{GaN}(\mathrm{P})_{\mathrm{II}}$. The domains have twin relation to each other and vary in thickness from $\sim 0.8$ to $\sim 2.5 \mathrm{~nm}$ and in length from $\sim 2$ to $\sim 10 \mathrm{~nm}$. 


\section{ACKNOWLEDGEMENTS}

The authors would like to thank Korea Ministry of Science and Technology (MOST) for financial support. The work at UCSD was supported by BMDO (Dr. Kepi Wu) monitored by USASMDC.

\section{REFERENCES}

1. G. B. Stringfellow, J. Cryst. Growth 27, 21 (1974).

2. K. Iwata, H. Asahi, K. Asami and S. Gonda, J. Cryst. Growth 175/176, 150 (1997).

3. W.G. Bi and C.W. Tu, Appl. Phys. Lett. 63, 3506 (1993).

4. S.M. Sze, Physics of Semiconductor Devices, 2nd ed. (John-Wiley \& Sons, New York, 1981).

5. D. Chandrasekhar, D.J. Smith, S. Strite, M.E. Lin, and H. Morkoç, J. Cryst. Growth 152, 135 (1995).

6. A. Trampent, O. Brandt, H. Yang, and K.H. Ploog, Appl. Phys. Lett. 70, 583 (1997).

7. I.-T. Bae, T.-Y. Seong, Y.J. Park, and E-K Kim, (unpublished).

8. D. Korakis, K.F. Ludwig, and T.D. Mustakas, Appl. Phys. Lett. 71, 72 (1997).

9. P. Ruterana, G. Nouet, W. Van der Stricht, I. Moerman, and L. Considine, Appl. Phys. Lett. 72, 1742 (1998).

10. T.-Y. Seong, I.-T. Bae, C.-J. Choi, Y. Zhao and C. W. Tu, Electrochem. \& Solid-State Lett., 2 94 (1999).

11. C-Y. Yeh, Z.W. Lu, S. Froyen and A. Zunger, Phys. Rev. B 46, 10086 (1992).

12. S. Strite and H. Morkoc, J. Vac. Sci. Technol. B 10, 1237 (1992).

13. Y. Xin, P.D. Brown, R.E. Dunin-Borkowski, C.J. Humphreys, T.S. Cheng, and C.T. Foxon, J. Crystal. Growth, 171, 321 (1997). 